\title{
A DIVERSIDADE DE GÊNEROS NA FORMAÇÃO DO PROFESSOR: (RE)CONHECENDO PRÁTICAS DE LETRAMENTO DE UMA PROFESSORA DE LÍNGUA PORTUGUESA (LP)
}

\author{
Milene Bazarim* \\ Adair Vieira Gonçalves**
}

\begin{abstract}
Resumo: Neste artigo, são apresentados e analisados diversos gêneros que foram produzidos por uma professora de LP em diversos contextos com o intuito de provocar uma reflexão sobre o impacto dos saberes que não são provenientes da formação inicial e/ou continuada na prática docente. Trata-se de uma pesquisa qualitativa, do tipo estudo de caso, cujos resultados apontam que os diversos mundos de letramento e seus entremeios são fundamentais para a compreensão sobre os usos da leitura e da escrita que ela faz enquanto professora de Língua Portuguesa. Informam esta pesquisa, entre outras, a concepção de linguagem e de gênero bakhtinianas, de letramento como um conjunto de práticas sociais situadas de uso da leitura e da escrita.
\end{abstract}

Palavras-chave: Formação do professor. Gêneros discursivos. Práticas de letramento.

\begin{abstract}
In this article, various genres are presented and analyzed, the ones which were produced by a Portuguese teacher in diverse contexts with the purpose of reflecting on the impact of knowledge that are not coming from initial and or/continued teaching practice. It is about a qualitative research of the case study type whose results inform that the diverse literacy worlds and their in-betweens are fundamental for the comprehension the Portuguese language teacher does of the reading and writing uses. This research also informs, among others, the Bakhtinian conception of language and genre, literacy as an established social practice in a specific context making use of reading and writing.
\end{abstract}

Keywords: Teacher training. Discursive genres. Literacy practice.

\section{Introdução}

Neste artigo é apresentada a diversidade de gêneros que fizeram parte da construção de um sujeito como professor de Língua Portuguesa (LP). Tendo em vista a impossibilidade de dissociar o gênero das práticas de letramento que o engendram, ao apresentar os vários gêneros, aponta-se também para os diversos mundos de letramento ${ }^{1}$ do professor $^{2}$. Tal diversidade, no entanto, é apenas sinalizada a partir desta pesquisa, já que certamente o sujeito de pesquisa produziu muitos outros gêneros aos quais não se teve acesso. Aqui, portanto, são apresentados resultados parciais de um estudo de caso, em andamento, sobre os efeitos de reversibilidade da escrita de uma professora e seus impactos no processo de ensinoaprendizagem de LP.

A professora, cujos registros são analisados, é graduada em Letras - Licenciatura em Língua Portuguesa, especialista em metodologia de ensino de LP e mestre em Linguística

\footnotetext{
* Mestre em Linguística Aplicada. Professora da Unidade Acadêmica de Letras da Universidade Federal de Campina Grande - UFCG. Endereço eletrônico: milene_bazarim@yahoo.com.br

** Doutor em Linguística e Língua Portuguesa. Professor da Universidade Federal da Grande Dourados. Endereço eletrônico: adairvgoncalves@gmail.com

${ }^{1}$ Segundo Tinoco (2003, p. 116), mundos de letramento "é a terminologia utilizada por Barton (1993) para esclarecer que todos os grupos sociais desenvolvem práticas culturais que favorecem habilidades específicas de leitura e de escrita. Sob essa perspectiva, não cabe o entendimento de que uma comunidade poderia ter maior ou menor nível de letramento, mas que cada uma apresenta orientações diferentes de letramento, daí a denominação 'mundos"'.

${ }^{2}$ Estamos compreendendo práticas de letramento como o faz Street (2014, p. 18). Tal conceito se coloca num nível mais alto de abstração e se refere igualmente ao comportamento e às conceitualizações sociais e culturais que conferem sentido aos usos da leitura e/ou da escrita.
} 
Aplicada $^{3}$. Desde o Curso de Especialização (BAZARIM, 2004; 2008b), dedica-se, mesmo que não de forma explícita, ao estudo sobre a mobilização dos saberes docentes e seus impactos no processo de ensino-aprendizagem, sobretudo da escrita, de LP. Com base na análise de um corpus constituído por 283 documentos (textos de diferentes gêneros que contemplam a escrita de $\mathrm{M}^{4}$. de 1990 a 2007) e 04 relatos reflexivos orais coletados/gerados de 2004 a 2010, tornou-se um problema de pesquisa a relação com a escrita construída por um sujeito para, ao se tornar professor, escrever não só as cartas para seus alunos, as quais foram objeto de estudo no mestrado (BAZARIM, 2006a; 2006b), mas também sequências didáticas ${ }^{5}$, ofícios, atas, projetos, relatórios, etc. O objetivo da pesquisa, por conseguinte, passou a ser descrever e analisar como M. se construiu como um sujeito com uma boa relação com a escrita, a qual lhe possibilitava escrever vários gêneros de complexidades diferentes, e quais as implicações que isso teve na sua prática profissional.

A pesquisa apresenta-se pertinente ao investigar a complexidade ${ }^{6}$ envolvida no processo de letramento de uma professora de LP. Os resultados da análise dos registros têm evidenciado que o processo de letramento de M., para se tornar uma professora com boa relação com a escrita, não começa na formação inicial e/ou continuada, mas sim na escola básica, na família e em outras atividades profissionais, como atestam Gonçalves et al ${ }^{7}$ (2016). Com isso, tais resultados apontam que a afinidade do professor de LP com a escrita e sua ação no processo de ensino-aprendizagem dependeria, muito mais do que se imagina, do que foi (re)construído no seu processo de letramento fora do contexto acadêmico e profissional (docente).

Após esta breve introdução, há uma seção para discutir, ainda que de forma sucinta, aspectos metodológicos da pesquisa; em seguida, há a apresentação e análise dos gêneros escritos por M. Encerrando o artigo e iniciando uma nova discussão, há alguns apontamentos.

\section{Sobre a construção do objeto de pesquisa}

\footnotetext{
${ }^{3}$ De 2004 em diante, o seu contato com as pesquisas realizadas no âmbito da Linguística Aplicada (LA), aliado ao seu retorno à sala de aula como professora efetiva de LP da rede estadual de São Paulo, fez surgir a possibilidade de constituir um corpus de pesquisa com registros gerados na sua sala de aula. O objetivo da pesquisa até aquele momento era identificar os significados da inovação nas aulas de LP e seus impactos no letramento escolar dos alunos. Como a retroação é um movimento possível nas pesquisas em LA, no segundo semestre de 2010, houve uma reconfiguração da pesquisa e o foco passou a ser o próprio processo de letramento da professora e seus impactos na sua prática profissional.

${ }^{4}$ Apesar de os papéis de professora e pesquisadora serem desempenhados pelo mesmo sujeito, já que uma parte dos registros foi gerada por meio de uma pesquisa-ação, neste artigo, a opção é de se referir à professora e sujeito de pesquisa, como "a professora" ou simplesmente M. Sem falsas expectativas sobre a "neutralidade" e "objetividade" da pesquisa, essa foi a melhor opção encontrada, até o momento, para garantir a legibilidade do texto.

${ }^{5}$ Conforme Dolz, Noverraz e Schneuwly (2004, p. 97), entendemos Sequência Didática como "um conjunto de atividades escolares organizadas, de maneira sistemática, em torno de um gênero textual oral ou escrito".

${ }^{6}$ A palavra complexidade, que aparece em várias ocasiões neste trabalho, não é utilizada em seu sentido comum, referindo-se à complicação ou confusão, mas como um macroconceito que traz em seu bojo a tolerância às incertezas, às indeterminações e aos fenômenos aleatórios (MORIN, 2007, p. 8). Neste trabalho, o termo complexo assume o mesmo sentido proposto por Morin $(2002$, p. 16) "o que está tecido em conjunto". Ao utilizar esse termo, ressalta-se que "é preciso aceitar certa imprecisão e uma imprecisão não apenas nos fenômenos, mas também nos conceitos.” (MORIN, 2007, p. 36).

7 Gonçalves et al (2016, p. 37) argumentam que os saberes docentes constituídos durante a didatização, na Educação Básica, de práticas de produção escrita, visibilizados durante o estágio de docência de estudantes em Letras, "resultam da interação entre forças ou atores sociais de natureza diversa, representantes não apenas das instituições de ensino diretamente envolvidas, mas também de outras instituições pelas quais passam os alunos-mestres ao longo da própria história de vida responsável pela identidade híbrida que os constitui”. A esses espaços denominam entremeio.
} 
Ainda que o processo de letramento e os textos materializados em diversos gêneros sejam objeto de análise, como legitimar uma pesquisa acadêmica, no âmbito da Linguística Aplicada (LA), em que os papéis de "pesquisador" e "pesquisado" são exercidos pelo mesmo sujeito? Essa transgressão aos "modelos tradicionais" de pesquisa científica só é possível se aderirmos a uma concepção de LA transgressiva, "[uma LA] como uma abordagem mutável e dinâmica para as questões da linguagem em contextos múltiplos, em vez de como um método, uma série de técnicas, ou um corpo fixo de conhecimento" (PENNYCOOK, 2006, p. 67). Uma LA transgressiva consiste em um modo de pensar e fazer sempre problematizador e na construção de objetos de pesquisa híbridos, complexos e dinâmicos (mesmo que isso soe como redundância). Nessa concepção, há a consciência de que os objetos de pesquisa não são pré-existentes, mas são sempre resultado de uma construção, inteiramente relacionada não só às opções teórico-metodológicas de cada pesquisador, mas também às suas crenças e valores acerca do que é objeto de investigação. Assim, um determinado objeto de pesquisa é apenas um entre vários possíveis.

$\mathrm{Na}$ pesquisa, cujos resultados parciais são apresentados neste artigo, a trans (in)disciplinaridade, característica dos trabalhos em LA, também se faz necessária no campo metodológico. A triangulação ${ }^{8}$, procedimento utilizado durante a análise dos registros, é compreendida como essencial para a construção de um objeto de pesquisa cuja complexidade já se apresenta no necessário cruzamento de diferentes metodologias: etnografia, pesquisaação e estudo de caso.

Em geral, nas pesquisas em LA, podem ser gerados e/ou coletados ${ }^{9}$ grande diversidade de registros ${ }^{10}$. No caso desta pesquisa, todos os registros, a partir de 2004, foram gerados por meio de uma pesquisa-ação, compreendendo, principalmente, a escrita de $\mathrm{M}$. como professora na esfera escolar. Há também quatro relatos orais sobre a história da escrita de M., os quais foram gerados no segundo semestre de 2010. Os registros coletados em 2010, no entanto, contemplam a escrita de M., sobretudo como aluna da escola básica, desde 1992.

Mesmo podendo ser considerada como um elemento dificultador, tal diversidade de registros transmite credibilidade às pesquisas que, assim como esta, seguem o paradigma qualitativo e utilizam elementos de metodologias em intersecção, como a pesquisa-ação, a etnografia e o estudo de caso.

Dado que a LA procura construir objetos de pesquisa cuja natureza é multifacetada e complexa, não é seguido um percurso de investigação que obedeça a um "programa fixo prémontado", mas um "plano" sempre orientado para as "regularidades locais" e para as "relações moventes" (SIGNORINI, 1998, p.102-103). O objetivo é manter a "especificidade", o "novo" e o "complexo" como elementos constituintes do objeto selecionado.

\section{3 (Re)Conhecendo os gêneros e os mundos de letramento de uma professora de LP}

\footnotetext{
${ }^{8}$ Triangulação, segundo Cançado (2004), é a análise de registros de diferentes naturezas a fim de identificar elementos que confirmem ou refutem determinadas hipóteses. Tal procedimento é necessário quando se tem o propósito de construir um objeto de pesquisa que, nos termos propostos por Signorini (1998, p. 103), "rompa com cadeias conceituais e expectativas teleológicas e totalizantes".

9 A diferença entre gerar e/ou coletar um registro está inteiramente relacionada ao grau de participação do pesquisador no que está usado para o estudo. Desse modo, é possível falar em coleta de registros se a única interferência do pesquisador residir no fato de que ele seleciona, dentro daquilo que já existe, o que lhe poderá ser útil. A geração de registros, entretanto, ocorre quando aquilo a ser estudado não existiria sem a participação do pesquisador.

${ }^{10}$ Registro é tudo que o pesquisador gera ou coleta a respeito da situação a ser estudada; já o dado é resultado da análise (portanto de seleção, de categorização e, consequentemente, de reduções). Logo, nem tudo que é registro se transforma em dado; ou ainda, os mesmos registros podem se tornar diferentes dados.
} 
O quadro a seguir mostra os gêneros produzidos em um espaço-tempo determinado de forma que se tenha uma hipótese de como foi o processo de letramento de $\mathrm{M}$. 


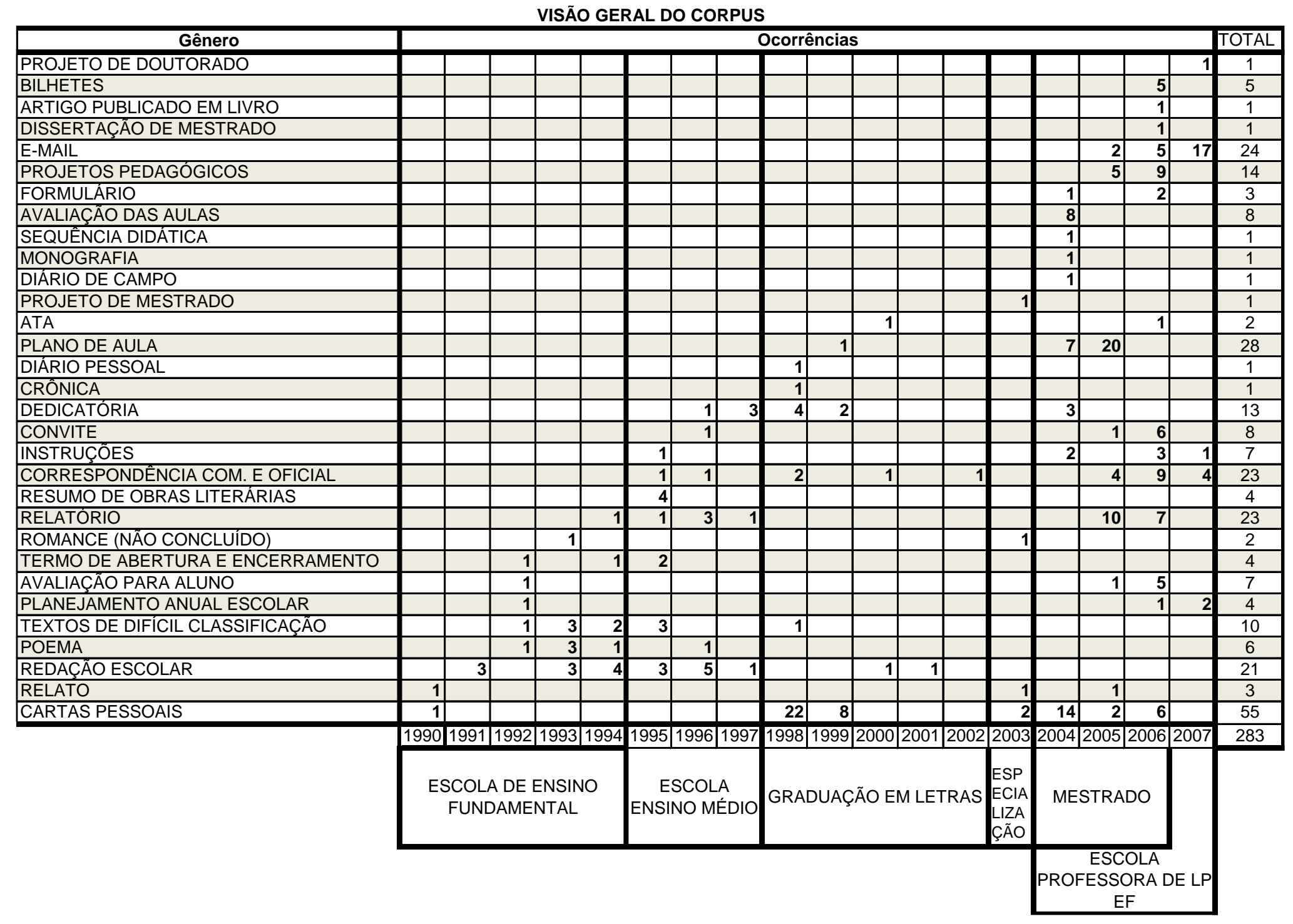


Aderimos aqui à concepção de gênero do discurso do Círculo de Bakhtin que, além da propalada relativa estabilidade, "emerge da totalidade concluída e solucionada do enunciado, que é o ato realizado por sujeitos organizados socialmente de uma determinada maneira. Trata-se de uma totalidade temática, orientada pela realidade circundante, marcada por um tempo e um espaço". (BRAIT; PISTORI, 2012, p. 383).

Evidentemente, não se pretende aqui aderir a uma visão engessada de gênero; ao contrário, é sabido que os gêneros são apenas relativamente estáveis, ou seja, o propósito é que a análise do seu caráter dinâmico receba mais ênfase que o estável. No entanto, neste trabalho, devido à necessidade de partir daquilo que é mais facilmente observável (o texto), ao analisar os diversos gêneros, reconhece-se, foi dada mais ênfase à estrutura composicional e a algumas marcas linguísticas que remeteriam ao estilo e autoria.

Não seria possível descrever todos os gêneros que apareceram no corpus. Por isso, é feito um agrupamento, mesmo sabendo de seu caráter temporariamente reducionista e que deve ser visto sempre como provisório. Para este trabalho, a classificação emergiu da análise dos próprios registros e da necessidade de se criar uma "vitrine" onde, se não todos, os mais significativos dos 31 gêneros identificados nos documentos do corpus pudessem ser apresentados. Essa metáfora é usada porque, tal como na vitrine de uma loja de roupas se encontram apenas alguns itens representativos e não todo o estoque, aqui também são apresentados os gêneros discursivos, quer pela sua recorrência quer pela sua singularidade, que são considerados representativos do corpus constituído.

Inicialmente, o corpus foi dividido em três partes: gêneros epistolares (134), gêneros não epistolares (145) e relato reflexivo oral (04). Por gêneros epistolares, entendem-se aqueles nos quais uma pessoa e/ou uma organização informa algo a alguém e/ou instituição. São correspondências, i.e.,

uma categoria que engloba diferentes formas de se trocar uma mensagem escrita, tais como cartas, postais, bilhetes, cartões de visita e fotografias (através da dedicatória), caracterizada também pela necessidade de resposta. (GERALDO, 2009, s/p).

De acordo com o campo de atividade humana, os gêneros epistolares estão divididos em: íntimo-pessoais (97) e comercial-oficiais (37). Foram considerados gêneros íntimo-pessoais: bilhetes, cartas pessoais, dedicatória, e-mail; já as cartas comerciais, ofícios, atas representam o campo comercial-oficial. Abaixo, seguem dois exemplos:

\begin{tabular}{|c|c|}
\hline 01 & Exemplo $02^{11}$ \\
\hline Emerson $^{12}$, & Itaquera 16 de dezembro de 1990 \\
\hline $\begin{array}{l}\text { Um livro é sempre um convite } \\
\text { para uma viagem. Nossa existência } \\
\text { é tão curta que não há tempo } \\
\text { suficiente para } \\
\text { EXPERIMENTAR, } \\
\text { ERRAR E APRENDER tudo. } \\
\text { Então, encontramos na leitura uma } \\
\text { alternativa para ver, experimentar, }\end{array}$ & $\begin{array}{l}\text { A minha mãe } \\
\text { Oi mãe, aqui é sua filha que está } \\
\text { escrevendo, pra saber se aí esta tudo bem, se a } \\
\text { senhora está com saudades de mim pois eu } \\
\text { estou de você. } \\
\text { Estou curiosa para saber quando a } \\
\text { gente vai mudar a senhora já sabe. }\end{array}$ \\
\hline
\end{tabular}

${ }^{11}$ Em Bazarim (2006a e b), encontra-se um estudo detalhado das cartas que M. trocou com seus alunos.

${ }^{12}$ Exceto o meu, todos os nomes que aparecem aqui são fictícios. 


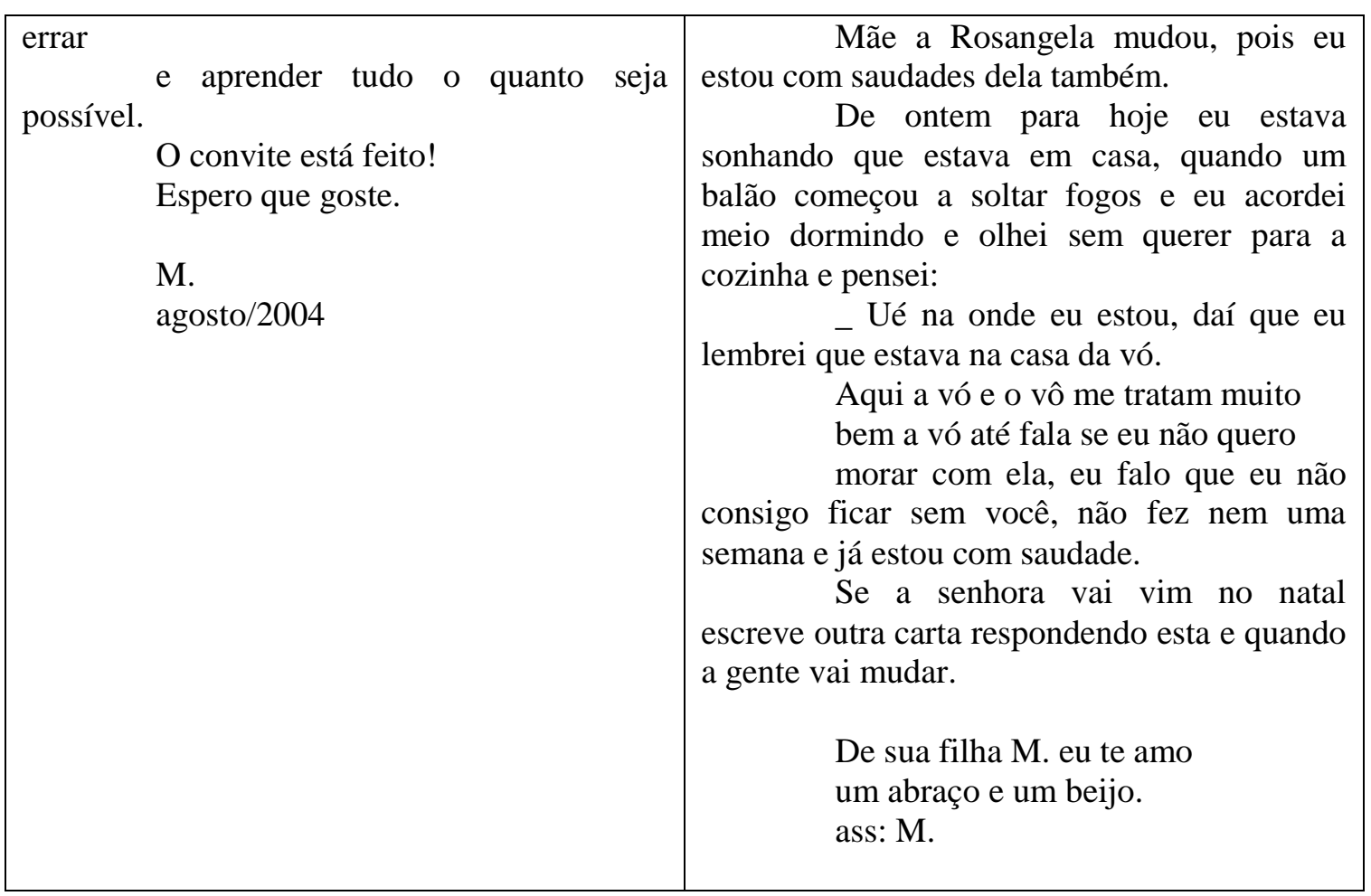

Fonte: Arquivo pessoal.

O Ex. 01 é constituído por uma dedicatória ${ }^{13}$ e o 02 por uma carta pessoal. Aqui, entende-se dedicatória como uma forma de escrita afetuosa que pode estar em um livro, em um cartão comemorativo, em uma fotografia etc. Ela geralmente marca eventos especiais como aniversário, casamento e lançamento de um livro etc.

As dedicatórias correspondem a $15 \%$ dos gêneros íntimo-pessoais no corpus analisado. Sua estrutura composicional é bastante regular: há uma abertura, um corpo de texto e encerramento. $\mathrm{Na}$ abertura, ao contrário da carta pessoal, não há local e data, apenas o nome, na forma de vocativo, daquele para quem a dedicatória é endereçada. No corpo do texto, além de felicitações, foram encontradas citações de poemas, salmos e frases de efeito ${ }^{14}$, tais como "O rio atinge seus objetivos porque aprendeu a contornar obstáculos" (LAO-TSÉ).

O Ex. 01 se diferencia dos demais porque não há uma felicitação. Somente pelo texto da dedicatória não se recupera o contexto, i.e., que se trata de uma dedicatória, presente no livro "Olhai os Lírios do Campo", de Érico Veríssimo, recebido por Emerson na ocasião do seu aniversário. Somente é possível saber que se trata de um livro, porque o texto se constrói como um convite à leitura. O encerramento, em todos os exemplos, é composto pela assinatura e data.

O Ex. 02 é uma carta pessoal escrita por M. para sua mãe aos onze anos de idade. Neste trabalho, assim como em Silva (2002, p.15), a carta pessoal é entendida como um gênero de "caráter essencialmente dialógico e dialogal, interativo e interlocutivo...", ela é "uma produção de linguagem, socialmente situada, que engendra uma forma de interação particular." (SILVA, 2002, p. 80). Sua estrutura composicional também é regular em relação à descrição que se tem das cartas pessoais (SILVA, 2002)

${ }^{13}$ Não estou considerando aqui as dedicatórias que aparecem em gêneros acadêmicos, tais como monografia, dissertação e tese.

${ }^{14}$ Nos exemplos analisados, essas frases de efeito são mixadas aos textos de M., sendo sua verdadeira autoria recuperável apenas em alguns casos em que não houve paráfrase. Há também aquelas frases que, apesar de autoria desconhecida, já foram consagradas pelo senso comum. 
e ao que aparece no corpus: há claramente identificável abertura (Itaquera 16 de dezembro de 1990/A minha mãe); corpo do texto (Oi mãe... a gente vai mudar) e encerramento (De sua filha M. eu te amo/um abraço e um beijo./ass: M.). O corpo do texto se constrói sobre temas do cotidiano e o contexto de produção é facilmente recuperável. M. está em férias na casa da avó aguardando ansiosamente por notícias sobre: a sua melhor amiga (que pode ter se mudado); a sua própria mudança (a qual foi planejada para dezembro de 1990, mas só ocorreria em maio de 1991); a chegada de sua mãe para as festividades de final de ano.

Em relação aos gêneros que fazem parte do campo de atividade humana comercial-oficial, apresentamos os exemplos 03 e 04.

\begin{tabular}{|c|c|}
\hline Exemplo 03 & Exemplo 04 \\
\hline $\begin{array}{l}\text { <logo da empresa> } \\
\text { <nome da empresa> } \\
\text { <departamento da empresa> } \\
\text { <endereço completo da empresa> } \\
\text { A quem possa interessar } \\
\text { Declaramos para os devidos fins que } \\
\text { M.prestou serviços a esta Cia. Como } \\
\text { estagiária, no período de } 12 \text { de abril de } 1996 \text { a } \\
\text { 28 de janeiro de 1998, exercendo as funções } \\
\text { desecretária. Durante o período que conosco } \\
\text { trabalhou não registramos fatos que a } \\
\text { desabone,tendo sua conduta sido irreprovável. } \\
\text { São Paulo, } 28 \text { de janeiro de } 1998 \\
\text { <assinatura> } \\
\text { <nome> } \\
\text { <função> }\end{array}$ & $\begin{array}{l}\text { <logo do governo e da escola> } \\
\text { <nome da secretaria> } \\
\text { <nome da coordenadoria> } \\
\text { <nome da escola> } \\
\text { <endereço completo da escola> } \\
\text { Campinas, 02 de janeiro de } 2007 . \\
\text { Ofício n. }{ }^{\text {o: }} \\
\text { Assunto:Agradecimento } \\
\text { A escola, como sabemos, ainda é um } \\
\text { lugar privilegiado para o acesso aos livros. } \\
\text { Todavia, mais que professores entusiastas, } \\
\text { que estimulem o hábito da leitura, é preciso } \\
\text { uma biblioteca na qual um acervo } \\
\text { diversificado esteja disponível aos alunos. A } \\
\text { biblioteca escolar, portanto, pode ser encarada } \\
\text { como uma oportunidade para democratização } \\
\text { da cultura, e, por conseguinte, uma forma de } \\
\text { diminuir a distância entre os "letrados" e "os } \\
\text { excluídos". } \\
\text { No ano de 2006, graças a sua } \\
\text { colaboração, demos continuidade ao nosso } \\
\text { projeto de implantação da biblioteca escolar, } \\
\text { bem como aos demais projetos de leitura. Os } \\
\text { livros doados,certamente, constituem um } \\
\text { valioso instrumento na formação de alunos } \\
\text { críticos e aptos ao pleno exercício da } \\
\text { cidadania. } \\
\text { Dessa forma, agradecemos a sua } \\
\text { doação e esperamos contar com o seu apoio } \\
\text { em futuros projetos. } \\
\text { Atenciosamente, } \\
\text { <assinatura> } \\
\text { <nome> } \\
\text { <função> } \\
\text { <destinatário> }\end{array}$ \\
\hline
\end{tabular}


Mesmo estando sob o mesmo rótulo "gêneros epistolares" do campo comercial-oficial, são apresentados gêneros com estrutura composicional diferente: no Ex. 03 há uma declaração; no 04, um ofício. A declaração começa com a forma prototípica "a quem possa interessar" e não é numerada, já que se trata de uma declaração genérica cuja principal função é a de tornar pública, por escrito, a presença de M. na empresa, durante um determinado período, o cargo que ocupava e, principalmente, informar que não há fatos que desabonem sua conduta (FERREIRA, 2000, p.124).

Apesar de ser assinada pelo gerente, conforme trecho abaixo, a redação era uma das atribuições de $\mathrm{M}$.

(...) quando eu fui para o estágio na Cia [enquanto cursava o Ensino Médio Técnico em Secretariado], isso [o fato de estar aprendendo redação comercial e oficial no curso técnico] também foi muito útil, porque na Cia. eu escrevia CI [comunicação interna], que era um tipo de carta, mas que circulava nos departamentos, escrevia ofício, de redigir mesmo, não só de preencher lacuna, tinha desses dois tipos, tinham coisas que eram muito padrão, então você só trocava o endereço onde foi executado o serviço e tinha alguns que você precisava redigir mesmo. $\mathrm{O}$ gerente, que era engenheiro, sempre que redigia alguma coisa ele passava para as secretárias, no caso a Núbia, que era funcionária e eu estagiária. Como a Núbia dizia que eu estava com a cabeça mais fresca, quando ele passava o texto para que nós revisássemos a escrita dele, eu tinha total liberdade para mudar o texto e eu fazia isso. ${ }^{15}$ (Relato Reflexivo 01, p. 24).

Embora haja outras estruturas possíveis, o ofício exemplificado é numerado e tem um destinatário definido, mencionado somente ao final. Também há diferença em relação à data; no ofício, ela é colocada logo após o cabeçalho; na declaração, a data vem antes da assinatura. Sua principal função é a comunicação entre o serviço público com o serviço público, com particulares ou entre o superior hierárquico e seu subordinado. No Ex. 04, há a comunicação entre serviço público, a escola, e uma instituição privada com a finalidade de agradecimento (FERREIRA, 2000, p. 96).

As particularidades da declaração e do ofício já eram de conhecimento de M. desde o Ensino Médio, período em que foi estagiária em uma grande Companhia Paulista, por conseguinte, no papel social de professora, não lhe causava dificuldade ter de redigir um ofício tanto solicitando quanto agradecendo a doação de livros feita por uma grande empresa da região à escola.

Apesar da distância temporal, de serem produzidos em locais diferentes e com funções também diferentes, ambos os exemplos são harmônicos na estreita relação entre o material linguístico e os aspectos sócio-históricos das produções linguageiras em análise usando em sua redação um "tom" solene e oficial, característico da redação comercial e oficial. A declaração atende também ao critério da concisão e objetividade, fato não observado no ofício cujo corpo de texto não é regido por regras tão rígidas quanto às da declaração. Na declaração não há introdução, vai-se direto ao que se quer declarar; no ofício exemplificado, de forma diferente, há uma introdução, composta por dois parágrafos a respeito da importância da biblioteca escolar e da leitura na formação

\footnotetext{
${ }^{15}$ Para se tornarem mais legíveis, todos os trechos dos relatos orais foram retextualizados. Houve bastante cautela para não haver alteração no conteúdo, apenas na forma.
} 
dos alunos e somente no último parágrafo há, de fato, o agradecimento pela doação de livros, objetivo do ofício que fora anunciado no assunto.

Os gêneros não epistolares também foram agrupados por campo de atividade humana: 97 da escola (plano de aula, planejamento, projeto pedagógico, avaliação, etc.); 09 da literatura (poemas, conto, crônica e romance) e 29 da academia (monografia, projeto de mestrado, projeto de doutorado, diário de campo etc.). Mesmo com essa tentativa de agrupamento, alguns gêneros híbridos (10), que não puderam ser classificados sob algum rótulo encapsulador específico, ficaram no grupo que intitulamos, para efeitos de análise, de "textos de difícil classificação".

No campo escolar, houve uma distinção entre gêneros da escola, ou seja, que a escola produz, tal como exemplo 07, e gêneros escolarizados, que são transformados em objeto de ensino, conforme exemplo 05.

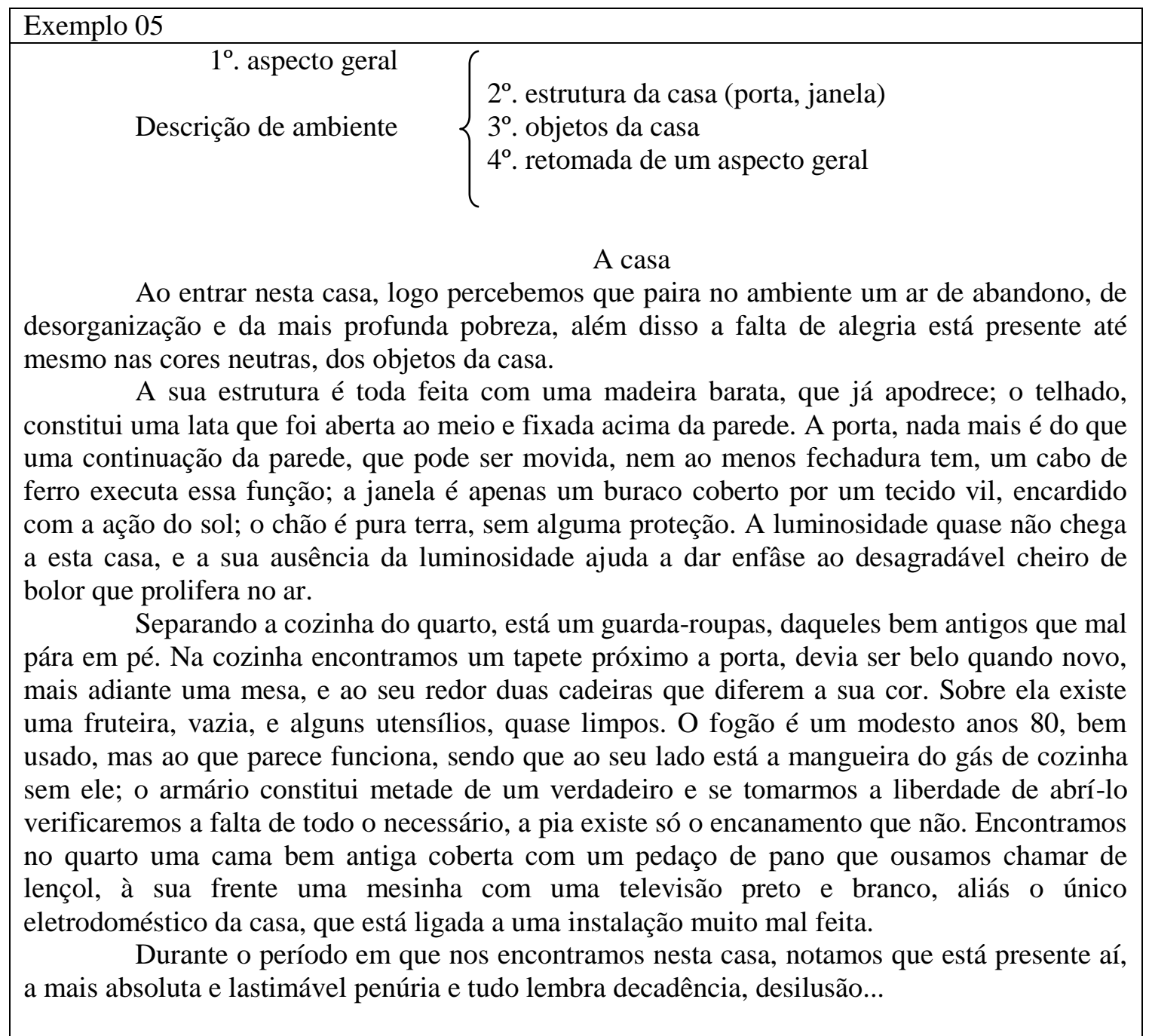

Fonte: Arquivo pessoal, 1993.

Dos 97 gêneros do campo escolar, 22\% são redações escolares escritas por M. Schneuwly e Dolz (2004, p.76) defendem que, nestes casos, "a comunicação desaparece, em prol da objetivação, e o gênero [e aqui inserimos a redação escolar] torna-se uma pura forma linguística, cujo domínio é o objetivo" (destaque dos autores). 
No exemplo 05, tem-se uma redação escolar do tipo descrição de ambiente ${ }^{16}$ produzida quando ela estava na sétima série. Trata-se de um rascunho, porque não há marcas de correção de um professor nem nota. Além disso, há anotações na parte superior do texto que são utilizadas como um lembrete do esquema que deve ser seguido nesse tipo de redação. Esse mesmo modelo é encontrado no caderno do segundo ano do Ensino Médio, Ex. 06, em que "Descrição" é definida como a redação na qual "apontam-se características de um determinado objeto, pessoa, ambiente ou paisagem".

\begin{tabular}{|c|c|}
\hline Exemplo 06 & \\
\hline 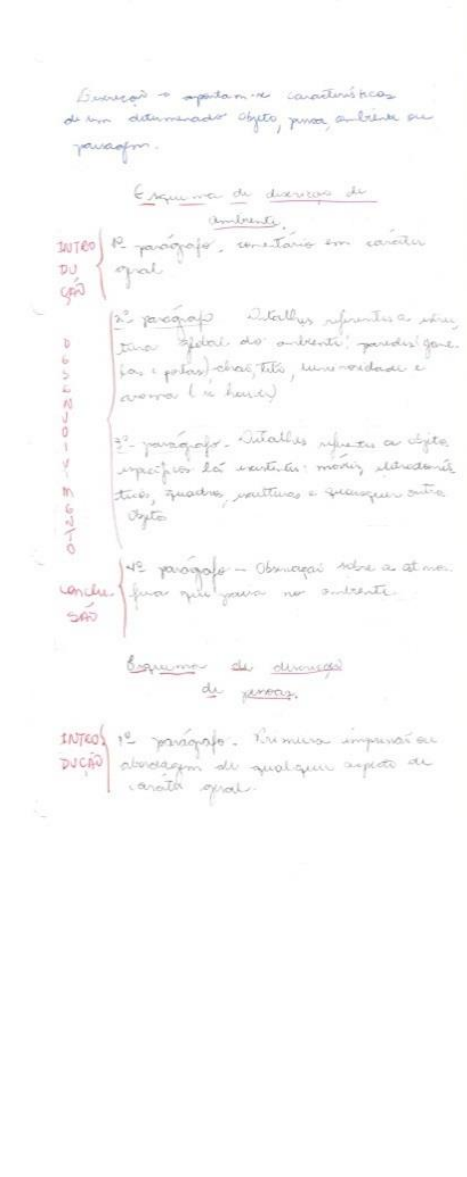 & 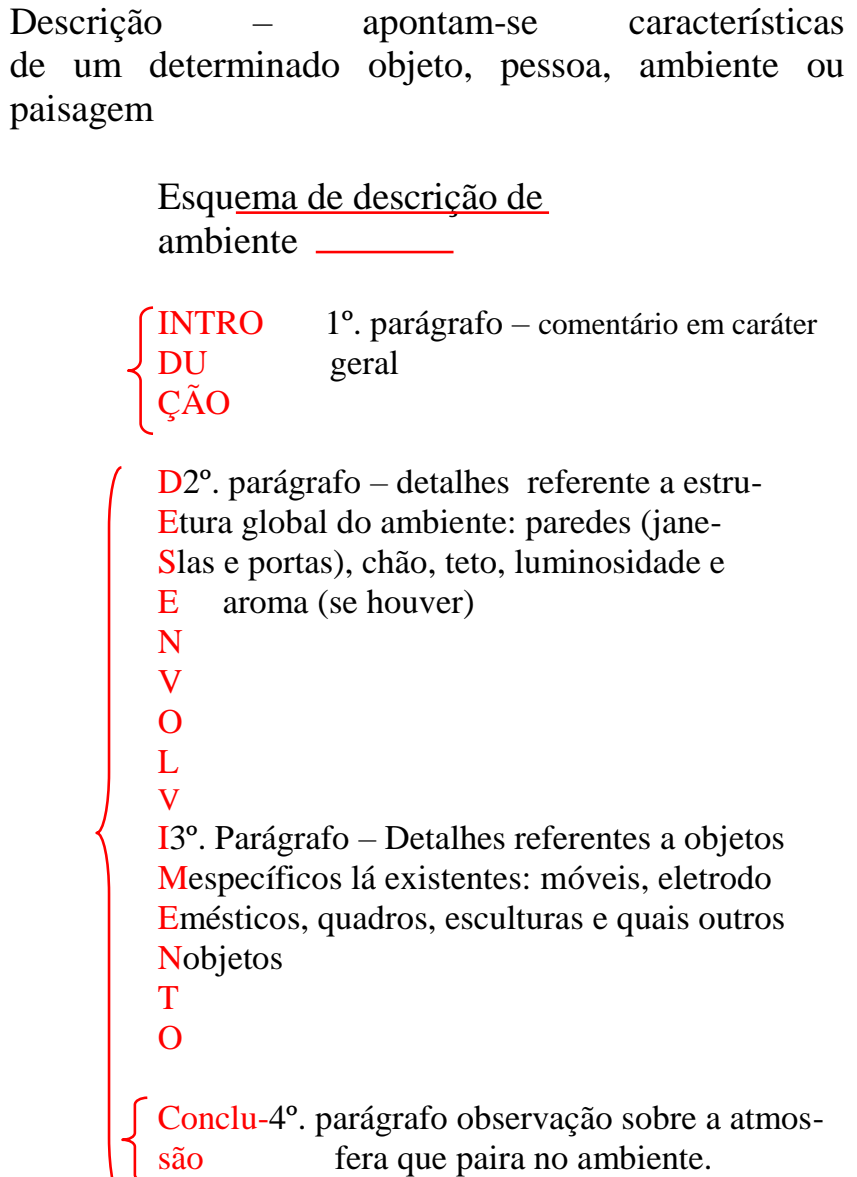 \\
\hline
\end{tabular}

O que se vê nesse esquema é uma descrição "pura", completamente desvinculada de um contexto específico. Diferentemente do que aponta Garcia (1981), para o qual a descrição e a narração frequentemente se permeiam de forma bastante semelhante ao que se encontra no caderno de M., Souza; Carvalho (1995, p.113-114) afirmam que

A descrição, ao contrário da narração, apresenta um aspecto estático. $\mathrm{O}$ objetivo do texto descritivo é bastante semelhante àquilo obtido com a fotografia. (...) $\mathrm{Na}$ descrição ambiental, há uma revelação

\footnotetext{
${ }^{16} \mathrm{Já}$ afirmamos que estamos vinculada teoricamente aos estudos bakhtinianos de gêneros; no entanto, os registros encontrados e analisados se filiam a outro referencial teórico, em que os textos são classificados segundo a tipologia: narração, descrição e dissertação. Esses três tipos correspondem ao que aqui entendemos como redação escolar. Portanto, desfaz-se uma aparente contradição: não podemos analisar a descrição tendo em vista as concepções bakhtinianas, se o texto não foi produzido segundo tal referencial teórico.
} 
objetiva ou subjetiva da maneira pela qual o autor exterioriza o que sente e o que vê, sem ser necessariamente uma fotocópia do que viu. Assim, elementos conotativos e denotativos podem estar conjugados.

Portanto, ao colocar o esquema no quadro e ao solicitar a escrita da descrição, o professor de M. não estava desprovido de uma "teoria" que legitimasse a sua prática. Embora bem escrito e coerente, o texto de M. não vai além do modelo apresentado.

Se no Ex. 05 há um gênero escolarizado, a redação escolar, n/ 07, tem-se como exemplo um gênero que a escola produz (ou se produzia). Conforme denominado pela própria professora M., trata-se de um resumo do projeto para participação no concurso "Escrevendo o Futuro".

Em 2006, o concurso, que mais tarde se transformaria nas Olimpíadas de Língua Portuguesa, era de adesão voluntária e somente participavam alunos de quartas e quintas séries, os quais poderiam produzir três gêneros: poesia, memórias e artigo de opinião. Na escola, os alunos das quartas séries optaram por memórias; os das quintas séries, por artigo de opinião. Ao final de etapa escolar, houve um evento para a escolha e premiação dos três melhores textos de cada gênero; no entanto, apenas um texto de cada gênero pôde representar a escola na etapa regional. Nenhum dos textos produzidos na escola foi selecionado na etapa regional.

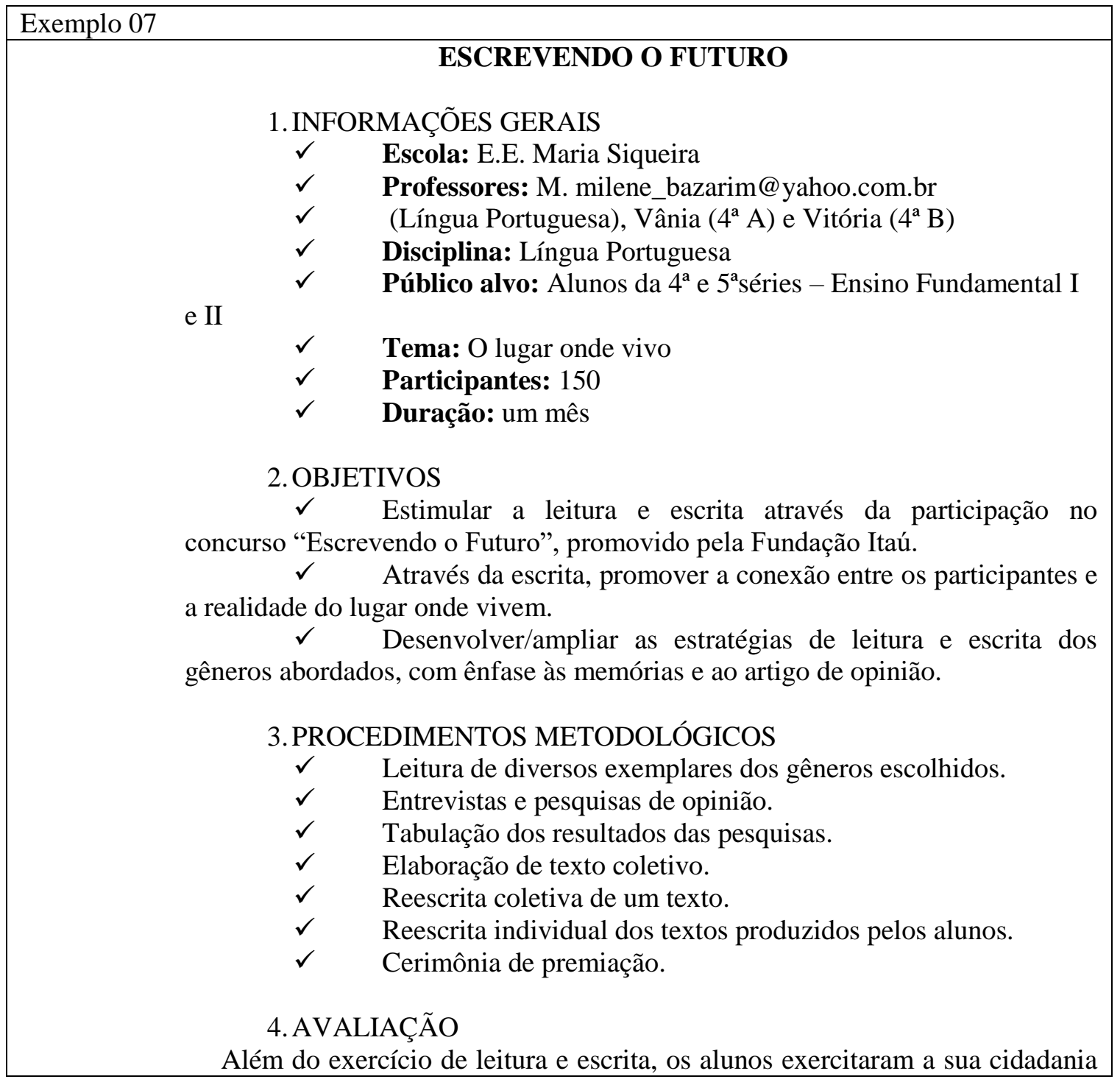


e capacidade de refletir sobre a escola e o bairro. A motivação para a realização das atividades se deu em virtude da participação no concurso, mas também pelo fato de os alunos terem a oportunidade de falarem de assuntos presentes na sua realidade imediata.

O principal objetivo da cerimônia de premiação era, não apenas selecionar os textos que representariam a E.E. Prof. ${ }^{a}$ Maria Siqueira, mas também compartilhar as produções com os demais alunos, professores da escola e com a comunidade em geral.

Fonte: Arquivo pessoal, 2006.

Os projetos pedagógicos correspondem a $15 \%$ dos gêneros escolares. Um projeto pedagógico geralmente se manifesta como uma carta de intenções e apresenta vocação descritiva, visto que informa quais serão as ações realizadas e como. No entanto, a presença da avaliação, já no projeto, mostra que a sua redação foi realizada posteriormente ao evento, caso em que seria mais adequada a produção de um relatório. Com isso, não se sabem que ações e objetivos foram inicialmente propostos, mas não alcançados. Mais relevante de que o fato de haver, neste exemplo, pouco espaço para a reflexão a respeito das ações, salienta-se a relação intergenérica entre projeto e relatório, entendida aqui como uma mistura de formas e de funções comunicativas de um gênero em outro gênero ou ao que Corrêa (2006, p. 5) denomina por ruínas, devendo estas ser compreendidas como "partes mais ou menos informes de gêneros discursivos, que, quando presentes em outro gênero, ganham o estatuto de fontes históricas retrospectivas ou prospectivas - da constituição de uma fala ou de uma escrita"

No Ex.08, a seguir, é apresentado um poema escrito por M. Trata-se de uma escrita automotivada.

\begin{tabular}{|ll|}
\hline Exemplo 08 & \\
\hline & Menino de rua \\
& Minha casa \\
& retrata uma imensidão \\
tenho todas as ruas & e nenhuma mansão \\
& Minhas roupas \\
& não são compradas \\
& são apenas pedaços de pano \\
& que no lixo foram achados \\
& O meu alimento \\
& Não é mamãe que faz \\
& Uma pessoa qualquer joga \\
& E a minha fome ela satisfaz \\
& Você deve estar espantado \\
mas eu não & você tem família, casa e comida \\
e eu nem sua compaixão & \\
Sou apenas \\
um menino de rua \\
e não se preocupe \\
porque a culpa também é sua.
\end{tabular}

Fonte: Arquivo pessoal, 1993. 
Os gêneros literários produzidos por $\mathrm{M}$. correspondem a apenas 3,2\% do corpus, sendo que sua ocorrência, na forma de poema ${ }^{17},(67 \%)$ foi maior entre 1992 a $1996^{18}$. No Ex. 08, tem-se um poema de versos livres, composto por 05 estrofes. Embora, para ser considerado poema, não seja obrigatório o uso de rimas, M., na ocasião com 13 anos, faz um esforço para construí-las entre o segundo e o quarto verso de cada estrofe. Ao contrário dos demais poemas, que são mais introspectivos e falam dos sentimentos de M., esse trata de um problema social.

Folheando seu caderno da sétima série, não foram encontrados outros poemas, contos ou crônicas com o qual pudesse ser estabelecida uma relação interdiscursiva clara. Com esse poema, observa-se uma tentativa de M. sensibilizar o leitor para um grave problema social, mas também se encontra uma contrapalavra ao discurso da mídia, o qual geralmente associa menino de rua ao consumo de drogas e a furtos e roubos. M. não faz essa associação, ao contrário, ela tenta dar voz ao menino de rua.

Além dos poemas, houve a produção de uma crônica e duas tentativas de produzir um romance, abaixo é reproduzido um trecho de um deles.

Exemplo 09

Eu e os outros

1 A idéia é justificar essas

lágrimas no próximo

capitulo. Posso colocar

nosso personagem em uma

situação grotesca que justifique essa vontade de não ter existido.

Ia caminhando lentamente, com passos firmes. Eu seguia. Inabalável e só. Pouco reconhecia daquele lugar, as vagas lembranças que me ocorriam passavam tão rapidamente que mal podia discerni-las. Já não era completamente noite, havia poucas pessoas nas ruas, agora tão calmas. $\mathrm{O}$ acender das luzes em algumas casas alternadamente clareava os arredores como pequenos sóis. Parei

Chove muito.

O dia parecia que não queria nascer. Ele veio derramando as águas de sua contrariedade. Lágrimas. De tristeza, de insatisfação, de arrependimento, de... covardia. E se o meu pai não tivessse ido àquele baile, ou se tivesse ido, mas com a sua esposa.

Os dois entrariam de braços dados. Ele com o seu melhor terno, talvez o cinza, cujo caimento salientava a sua elegância. Pouco importava que os seus fartos cabelos grisalhos denunciassem os anos vividos se tudo nesse homem exalava o vigor da juventude que ele lutava com todas as forças para não deixar escapar. Ela também se apresentava bela e mesmo a sua discrição de jovem senhora não impedia a qualquer um perceber a alegria e o orgulho que sentia por estar ao lado de tão digna criatura. Desembarcaram do Alfa Romeo à porta do salão. Quando da entrada de tão distinto casal, a música parecia ter sido interrompida, todos abriram passagem para o par que logo se dirigiu ao centro. Iniciada a nova seleção. A essa hora o bolero caiu muito bem. Veja em que egoísmo mergulhou aquele casal, riscando o salão como se somente a ambos ele pertencesse, despertando invejas como se aquela felicidade fosse

${ }^{17}$ Cabe salientar que foram colocados no campo da literatura aqueles gêneros que foram produzidos por M. com o propósito de serem literários. Não cabe aqui discutir que concepção de literatura sustenta essa decisão analítica, já que o que está em jogo não são as eventuais qualidades literárias (ou falta de) dos gêneros, mas sim o fato de eles terem sido produzidos como tal.

18 É digno de nota o fato de, em 1993, doze dos dezenove gêneros encontrados no caderno de Língua Portuguesa da sétima série serem poemas. 
privilégio apenas deles. Vieram outras seleções. Os outros acabaram contagiados e quando menos se deu conta todos mergulharam na mesma atmosfera. Terminada a última dança o casal despediu-se dos amigos e seguiu. Eles chegaram em casa e tudo se passou como se aquela jovem senhora há pouco não tivesse deixado definitivamente sem mãe os seus próprios filhos.

Dessa forma não haveria história, quer dizer haveria outra história.

Fonte: Arquivo pessoal, 2003.

Entre essa e a primeira tentativa de escrever um romance, há um espaço de 10 anos. Diferentemente do que ocorreu em 1993, em 2003, houve um plano para a sua construção; no entanto, não ficam claras as motivações para o início da escrita e para a sua não conclusão.

O que M. pretendia, com base no seu plano, era construir um gênero permeado por outros gêneros, constituído por lembranças esparsas de um Eu que está retornando a algum lugar depois de muito tempo ausente. A noção de tempo linear seria completamente subvertida, a história de uma vida seria contada em flashes que durariam poucos minutos.

Até o final do romance, não seria revelado que o Eu estaria voltando para sua casa nem o motivo do retorno: o funeral do seu pai. Nesse caminho até sua casa esse Eu reflete sobre a sua existência e passa a buscar também um significado para a sua vida. Tal fato ocorre quando, ao chegar a casa e se deparar com o caixão, o Eu percebe que tem de enterrar a sua história passada e tomar para si as rédeas do seu presente e futuro. Propositadamente, há uma grande tentativa de não haver distinção entre masculino e feminino, trata-se apenas de um Eu qualquer que, assim como muitos outros, está buscando compreender a si próprio pela sua história.

Contemplando $16 \%$ do corpus, os gêneros do campo da esfera acadêmica têm se tornado, dada a sua diversidade e heterogeneidade, os mais difíceis de definir e exemplificar. A formulação de um gênero do campo acadêmico

depende de uma pesquisa minuciosa e efetiva sobre um objeto que é metodologicamente analisado à luz de uma teoria. (...) A comprovação ou a refutação do que foi escrito dar-se-á por meio da aceitabilidade do público que compõe a comunidade específica. (CARIOCA, 2008, p. 827).

Mesmo considerando a diversidade e heterogeneidade desses gêneros, é possível dizer que, além do campo de atividade humana, eles compartilham algumas características, tais como normatização e convenção. Carioca (2008, p. 835) sugere que a intertextualidade, a interdiscursividade e a argumentatividade são as principais características dos gêneros acadêmicos. Do ponto de vista estritamente linguístico, eles compartilham também o fato de serem constituídos por citações e paráfrases e por um sujeito pesquisador-autor que ora se mostra ora se esconde (CARIOCA, 2008).

Apesar de não constar como um gênero autônomo no corpus, exemplificamos abaixo não com a dissertação (por uma questão de espaço), mas com o seu resumo. Segundo Matêncio (2002, p. 112), quando, como nesse caso, o produtor do resumo é o autor do texto-base, ele tem mais liberdade para alterar forma e conteúdo. Ainda segundo a mesma autora (MATÊNCIO, 2002, 115-116), resumos de artigos acadêmicos, dissertações e teses podem ter pouca subordinação em relação à estrutura do texto-base porque nesse tipo de resumo o que está em jogo não é a seleção de macroestruturas do texto-base, mas a apresentação daquilo que é principal tendo em 
vista os propósitos enunciativos do autor. Esse tipo de resumo, conforme exemplo 11, tem a função central de descrever o modo de realização do trabalho acadêmico.

Exemplo 10

\section{RESUMO}

Este trabalho apresenta os resultados de uma investigação sobre a construção da interação em mensagens escritas trocadas entre mim, enquanto professora, e meus 98 alunos de uma escola pública da periferia de Campinas-SP. Trata-se de uma investigação de cunho qualitativo na qual a geração dos registros foi orientada pela metodologia da pesquisa-ação. As 189 mensagens que constituem o corpus foram geradas durante o mês de novembro de 2004, sendo que 125 foram produzidas por mim e 64 pelos alunos de quinta e sexta séries. Inicialmente, essas mensagens eram curtas e visavam estabelecer um contato amigável entre professora e alunos. À medida que os alunos foram respondendo, as mensagens foram se individualizando, tornando-se mais longas e se aproximando do gênero carta pessoal. A troca de mensagens foi uma atividade extraclasse e os textos assim produzidos não foram objeto de correção ou discussão em sala de aula. As análises revelaram que nessas mensagens, embora os papéis institucionais de professora e aluno não tenham sido apagados, houve deslocamentos significativos e de grande interesse para a reconfiguração do contexto sociointeracional da sala de aula, pois procurei me construir como um interlocutor interessado no que o aluno teria a dizer sobre si mesmo e sobre a escola. Desse modo, a interação estabelecida escapa aos padrões escolares vigentes naquela instituição sem, contudo, deixar de ter um caráter institucional e pedagógico importante para o letramento do aluno, uma vez que houve também a mobilização de recursos lingüístico-discursivos necessários à interação via carta.

Palavras-chave: Interação professor-aluno, letramento, pesquisa-ação.

Fonte: BAZARIM, 2006a.

Em relação a sua estrutura composicional, os resumos de dissertação, assim como o exemplo anterior, são compostos por um corpo de texto e, ao final, as "palavraschave". No corpo do texto, é importante que se encontrem respostas para as seguintes perguntas: onde e como foi feita a pesquisa? Com quem? Com qual objetivo? Quais os resultados? Qual a contribuição do trabalho? No Ex. 10, tais perguntas são suficientemente respondidas. Como se trata de uma pesquisa-ação, o sujeito autorpesquisador mais se mostra do que se esconde.

Apesar da dificuldade, ainda foi possível esboçar uma definição dos gêneros do campo acadêmico que aparecem no corpus. O mesmo não acontece com o Ex. 11, um dos que ficou no grupo dos "textos de difícil classificação".

Exemplo 11

"Uma das coisas mais admirável de um ser humano é a sua capacidade de amar ao proximo e de comunicação, transmitindo assim a coisa que ele tem de melhor e que não precisa ninguem ensinar eu estou falando do amor, compreenção, sinceridade e carinho, que sempre deve existir entre as pessoas. Só que se tem algo de bom tem de ruim, o homem destroi a si mesmo e a seu semelhante em uma guerra de ambição por coisas materiais, isso é terrivel pois o ser mais inteligente ter a capacidade de fazer isso enquanto existir pessoas assim o mundo continuará assim com todo esse racismo e discriminação. Mas se todo mundo parar para pensar verá que só precisa de um pouco de consciencia e insentivo para que todos aqueles que cometem tal coisa, prejudicial, veja que ele tem chances de se recuperar, e de amar como qualquer um e o amor e a amizade é uma dessas formas"

"Pense nisso"

M. 
Fonte: Arquivo pessoal, 1992.

Esse texto foi produzido quando $M$. tinha doze anos. Discursivamente, assemelha-se muito a uma carta (Ex. 02) escrita para a mãe em 1990. Trata-se de um texto confuso, principalmente devido à má utilização dos recursos da pontuação. $\mathrm{O}$ tema parece ser o amor, mas não há um fio condutor definido. M. se perde ao comparar o amor com a falta de amor, entrando em questões muito mais genéricas do que as que aparecem no início do texto. Ao contrário dos demais textos do corpus, aqui, fica clara a dificuldade em relação à grafia correta e à concordância, o que, aliado à dificuldade na pontuação, mostra que $M$. ainda estava na fase de aprendizagem da norma culta escrita.

O Ex. 11 se parece muito com uma redação escolar. Tendo sido encontrado na terceira capa do caderno, pode ser entendida como um texto do tipo "mensagem" bem genérico. Mesmo estando no caderno, parece um texto automotivado, cujos leitores, que são convidados a "pensar nisso" provavelmente fossem os próprios colegas de turma. Não se tratava de um caderno comum, no qual se registra a "matéria", mas um caderno em que cada colega podia deixar uma mensagem, respondia uma pergunta pessoal, elaborada por M., e também podia lhe fazer alguma pergunta. Circulava no campo escolar, mas não se parece um típico gênero escolar.

Dois anos depois, o texto foi completamente reescrito, conforme exemplo abaixo.

\section{Exemplo 12}

Uma das coisas mais admiráveis em um ser humano é poder dizer o que você pensa, transmitir o que você sabe, aprender o que não sabe.

Por mais que você saiba, nunca esse saber é o bastante pois nos caminhos da vida, cada tempo é tempo de se aprender uma coisa nova

Nesse caminho você aprende a dar valor as coisas que te rodeiam e as palavras que ouve, mesmo sem saber quem as diz, pois da vida todos nós sempre seremos um aprendiz

Não se limite em aprender, é sempre bom saber sobre você e sobre aqueles eu te rodeiam.

Leia bons livros, faça amigos, ame a você mesma, e ao seu semelhante, procure aprender com que já sabe. irá aprender.

Só que a lição da vida, só ela sabe lhe ensinar e ninguém saberá te explicar, mas você

Procure que você achará uma razão...

Uma razão... para viver

M.B.

Fonte: Arquivo pessoal, 1992.

Nesse texto, que estava ao lado do Ex. 11, foram encontradas marcas de revisão (o que é foco de outro estudo). Dois anos após a "primeira versão", houve uma reescrita total, podemos dizer que se trata de outro texto, mas com a mesma forma e propósito reflexivo. Apesar de igual na generalização, há um fio condutor mais bem definido. Além disso, em termos de recursos linguístico-discursivos, percebe-se um avanço: não há mais tantas dificuldades na pontuação, na grafia, tampouco na concordância, apresentando-se mais coeso e coerente.

Além dos 283 documentos escritos, fazem parte do corpus 04 relatos reflexivos orais, nos quais M. conta a sua história de/com a escrita. Apesar de serem orais, os relatos reflexivos são concebidos como "um gênero catalisador na explicitação, organização e ressignificação da experiência passada à luz de indagações e inquietações 
do presente" (SIGNORINI, 2006, p. 68-69). Também nos termos propostos por Signorini (2006), entende-se por catalisadores

gêneros discursivos que favorecem o desencadeamento e a potencialização de ações e atitudes consideradas mais produtivas para o processo de formação, tanto do professor quanto de seus aprendizes. (SIGNORINI, 2006, p. 8).

A seguir, são apresentados dois trechos como exemplo.

Exemplo 13

(...) eu não tinha uma nota vermelha, eu era a aluna mais caxias que existia na $5^{\mathrm{a}} \mathrm{E}$ quem organizava a sala era eu (...) (Relato reflexivo 1, p.19)

(...) então, eu achava que seria legal ser professora, as pessoas diziam que eu até levava um jeito e eu dizia ser professora é uma coisa boa, né? Ganha bem, é uma profissão valorizada socialmente. Eu acreditava que era valorizada, eu valorizava tanto meus professores, minha mãe valorizava tanto os professores. O Prof. Márcio, de literatura de Língua Portuguesa lá do Presidente Getúlio Vargas, tinha falado pra gente que tinha um excelente padrão de vida e ele sempre foi professor e ele se orgulhava de ser professore a gente se orgulhava de ter um professor que nem ele, entendeu? Porque ele nunca reclamou de salário (...) (Relato reflexivo 3, p.2-3)

Fonte: Arquivo pessoal, 2010.

Os relatos reflexivos foram gerados a fim de elucidar os elementos da história de vida de M. que apontam para a construção de uma relação de familiaridade com a escrita. Nesses dois trechos, é possível perceber a apreciação valorativa de M. sobre si mesma e sobre a profissão, sobretudo pelo uso de expressões predicativas. No primeiro trecho, é possível perceber que M. se mostra confiante e tem uma apreciação valorativa positiva a respeito de si mesma em relação ao seu rendimento escolar. Além de ressaltar que não tem notas baixas, se coloca como a melhor aluna da turma. Tal apreciação valorativa positiva também aparece quando $M$. se refere à profissão, para ela ser professora é bom, porque tem um bom salário e se trata de uma profissão valorizada socialmente, o que pode lhe dar o mesmo excelente padrão de vida que seu professor disse ter.

\section{Considerações finais}

Conforme o anunciado na Introdução, o objetivo deste artigo era apresentar e analisar (alguns) gêneros que fizeram parte do processo de letramento de uma professora de LP. Essa diversidade de gêneros indica algumas das diversas práticas de uso da leitura e da escrita das quais a professora participou e que podem ser fundamentais na compreensão dos usos da leitura e da escrita que ela faz enquanto professora de LP e que são constitutivos dos mundos de letramento de M.

Por não se concentrar na apropriação de saberes provenientes apenas da formação inicial e/ou continuada, os resultados aqui apresentados são significativos para que se consiga perceber o sincretismo (TARDIF, RAYMOND, 2000), o entremeio, na acepção de Goncalves et al. (2016) que constitui os saberes docentes. E, além disso, pode ser o ponto de partida para que os cursos de formação inicial e continuada de professores de LP consolidem espaços em suas grades curriculares para que haja o 
fortalecimento e/ou ampliação da relação dos professores em formação com práticas de leitura e escrita.

\section{Referências}

BAZARIM, M. O texto na sala de aula: o modelo nas séries iniciais. In: II Simpósio Nacional de Estudo dos Gêneros Textuais - SIGET, 2004, União da Vitória-PR. Anais do II SIGET. União da Vitória-PR: Faculdade Estadual de Filosofia, Ciências e Letras, 2005. p. $1-8$.

.Construindo com a escrita interações improváveis entre professora e alunos do ensino fundamental de uma escola pública da periferia de Campinas. Dissertação de Mestrado inédita. Campinas: Unicamp/IEL, 2006a.

. A construção da interlocução entre professora e alunos em contexto escolar. In: SIGNORINI, I. Gêneros catalisadores, letramento e formação do professor. São Paulo: Parábola, 2006b, p.19-52.

Metodologias de pesquisa aplicadas ao contexto de ensino-aprendizagem de Línguas. In: XII Congresso Nacional de Linguística e Filologia. Rio de Janeiro: 2008a, v.01, p.93-102. Disponível em:http://www.filologia.org.br/xiicnlf/textos_completos/Metodologias\%20de\%20pesqu isa\%20aplicadas $\% 20 \mathrm{ao} \% 20$ contexto $\% 20 \mathrm{de} \% 20$ ensinoaprendizagem\%20de\%20línguas\%20-\%20MILENE.pdf

A interação professora-alunos mediada pela escrita com um elemento da inovação nas aulas de língua materna (LM). In: XV Congresso Internacional de La Asociación de Linguistica y Filologia de America Latina - ALFAL. Montevideo: Atas XV Congresso da ALFAL, 2008b, v. 1. Disponível em: $<$ http://alfal.easyplanners.info/programa/programaExtendido.php?casillero $=522083000$ $\&$ sala $=$ Sala\%202501\&dia $=$ =Miércoles\%2020\%20de\%20agosto $>$. Acesso em 05 de dezembro de 2008.

BRAIT, B.; PISTORI, M.H.C. A produtividade do conceito de gênero em Bakhtin e o Círculo. Alfa. São Paulo- SP, v. 56, n. 2, p. 371-401, 2012.

CANÇADO, M. Um estudo sobre a pesquisa etnográfica em sala de aula. Trabalhos em Linguística Aplicada. Campinas-SP: Unicamp/IEL n. ${ }^{\circ}$ 23, p. 55-69, 2004.

CARIOCA, C. R. A caracterização do discurso acadêmico baseada na convergência da Linguística Textual com a Análise do Discurso. Unisul, 2008, p. 825-834. Disponível em: http://www3.unisul.br/paginas/ensino/pos/linguagem/cd/Port/36.pdf. Último acesso em: 12 de julho de 2010.

CORRÊA, M. L. G. Relações intergenéricas na análise indiciária de textos escritos. Trabalhos em Linguística Aplicada. Campinas, SP, v. 45, n²2, 205-224, 2006. 
DOLZ, J.; NOVERRAZ, M.; SCHNEUWLY, B. Sequências didáticas para o oral e a escrita: apresentação de um procedimento. In: SCHNEUWLY, B.; DOLZ, J. (Orgs.). Gêneros Orais e Escritos na Escola. Campinas, SP: Mercado de Letras, 2004, p.95-128.

FERREIRA, R. M. Correspondência comercial e oficial. 14. ed.São Paulo: Ática, 2000

GARCIA, O. M. Comunicação em Prosa Moderna. 9. ed. RJ: Ed. da Fundação Getúlio Vargas, 1981.

GERALDO, J. C. Lendo imagens e palavras: sociabilidades e afetos nas dedicatórias de retratos do acervo José Boiteux (Florianópolis 1890 - 1930). Anais do $17^{\circ}$. COLE (Congresso de Leitura do Brasil). Campinas: SP: ALB, 2009. Disponível em: http://alb.com.br/arquivo-

morto/edicoes_anteriores/anais17/txtcompletos/sem05/COLE_3436.pdf. Último acesso em: 11 de julho de 2011

GONÇALVES, A. V.; SILVA, W. R.; CAVALHERO, J. S. Produção escolar escrita em relatórios de estágio de uma licenciatura em letras. Linguagem em (Dis)curso. PalhoçaSC, v. 16, n. 1, p. 35-55, 2016.

MATÊNCIO, M. L. M. Atividades de (re)textualização em práticas acadêmicas: um estudo do resumo. Scripta, Belo Horizonte-MG, v. 06, n. 11, p.109-122, 2002. Disponível em: http://www.ich.pucminas.br/cespuc/Revistas_Scripta/Scripta11/Conteudo/N11_Parte01 _art08.pdf. Último acesso em 13 de julho de 2011.

MORIN, E. Introdução ao Pensamento Complexo. 3. ed. Porto Alegre, RS: Sulina, 2007. 2002.

. Educação e Complexidade: os sete saberes e outros ensaios. São Paulo: Cortez,

PENNYCOOK, A. Uma linguística aplicada transgressiva. In: MOITA-LOPES, L. P. Por uma linguística aplicada indisciplinar. São Paulo: Parábola, 2006.

SCHNEUWLY. B.; DOLZ, J. Os gêneros escolares: das práticas de linguagem aos objetos de ensino. In: Gêneros orais e escritos na escola. Trad. e (Org.). de Roxane Rojo e Glaís Sales Cordeiro. Campinas: Mercado de Letras, 2004. p. 71-91.

SIGNORINI, I. Do residual ao múltiplo e ao complexo: o objeto da pesquisa em Linguística Aplicada. SIGNORINI, I. ; CAVALCANTI, M. C. (Orgs.). Linguística aplicada e transdisciplinaridade. Campinas-SP: Mercado de Letras, 1998, p.81-98.

(Org.). Gêneros catalisadores: letramento e formação do professor. São Paulo: Parábola, 2006.

Os significados da inovação no ensino de língua portuguesa e na formação de professores. Campinas-SP: Mercado de Letras, 2007. 
SILVA, J.Q.G. Um estudo sobre o gênero carta pessoal: das práticas comunicativas aos indícios de interatividade na escrita de textos. (Tese de Doutorado). Belo HorizonteMG., Faculdade de Letras da UFMG, 2002.

SOUZA, L. M. de; CARVALHO, S. W. Compreensão e produção de textos. PetrópolisRJ: Vozes, 1995.

STREET, B. V. Letramentos sociais: abordagens críticas do letramento no desenvolvimento, na etnografia e na educação. São Paulo: Parábola, 2014.

TARDIF, M.; RAYMOND, D. Saberes, tempo e aprendizagem do trabalho no magistério. Educação \& Sociedade, ano XXI, n. 73, Dezembro/00.

TINOCO, G. M. A. de M. Passeio etnográfico pela linguagem escrita: em busca de legitimação da cidadania. Dissertação (Mestrado em Letras) - Programa de Pósgraduação em Estudos da Linguagem. Universidade Federal do Rio Grande do Norte, Natal. 2003.

Recebido em: junho de 2016.

Aprovado em: julho de 2016. 